\title{
ATTITUDES TOWARDS INNOVATIONS: EVIDENCE FROM WINE INDUSTRY ENTERPRISES
}

\author{
M. Angelova*, D. Pastarmadzhieva \\ Department of Management and Quantitative Methods in Economics, University of Plovdiv \\ Paisii Hilendarski, Plovdiv, Bulgaria \\ Department of Political Sciences and National Security, University of Plovdiv Paisii Hilendarski, \\ Plovdiv, Bulgaria
}

\begin{abstract}
The innovations take an essential role in the Bulgarian economic environment as well as in the national strategies for economic growth. For many companies, improving and increasing innovation and the ability to develop innovation is the most important factor for growth. The paper explores the innovation activity of the wine industry as a specific sector of the Bulgarian economy. The purpose of the current study is to identify the attitudes of the wine producers towards innovations and to discuss the innovation activity of their enterprises. The methods used include in-person verbal interviews, which were conducted with 15 participants as expert practitioners to test the ideas, build knowledge, and gain insightful context and nuance to the ideas. The results show that although some of the wine producers implement innovations they don't realize it. The focus of their innovations is in the product, process, and technological innovations, because they try to reach a balance between quality and price. It looks like that the institutions are more like obstacle rather than support for such activity. Thus, we can conclude that to a high extent the wine producers in Bulgaria are implementing and willing to implement innovations. However, they are not well aware of the possible innovations, their potential for increasing competitiveness and therefore are focusing only on directly improving their product.
\end{abstract}

Key words: innovation, innovation strategy, wine industry, interview

\section{INTRODUCTION}

The focus of the current paper, namely innovations and innovation strategies, takes a central position in discussions, researches, and organizational activities connected to the process of creating innovative enterprises. It takes an essential role in the Bulgarian economic environment as well as in the national strategies for economic growth. For many companies, improving and increasing innovation and the ability to develop innovation is the most important factor for growth. Innovation is a prerequisite for ensuring a higher level of economic development, but the problem of its more efficient management is still valid. This is even more difficult as innovations require a specific

\footnotetext{
*Correspondence to: Mina Angelova, Department of Management and Quantitative Methods in Economics, University of Plovdiv Paisii Hilendarski, Plovdiv 4000, Bulgaria, 24 Tsar Asen Str., +359887461272, mina.angelova@uniplovdiv.bg
}

Approach depending on the industrial sector because each industry and region have their own specificities (1).

The aim of the current study is to identify the attitudes of wine producers towards innovations and to discuss the innovation activity of their enterprises. Thus, the object of the research is managers and specialists from a convenience sample of small and medium-sized enterprises from wine industry positioned in Bulgaria. The focus is the possibility for enhancement of the Bulgarian wine industry and in particular by implementing innovations. The methods used include in-person verbal interviews, which were conducted with 15 participants as expert practitioners to test the ideas, build knowledge, and gain insightful context and nuance to the ideas. As the study is a part of a project KP 06M25/5/2018-2020, this paper presents the results of in-depth interviews and summation analyses. 
The article is structured as follows: following the introduction, in the second part is described the methodological framework for investigating the innovation activities. This analysis paves the way for the third part which is highlighted the results and discussion of the research. The article closes with conclusions and recommendations for future research in the field of investigation the innovation activities in the wine industry.

\section{METHODOLOGY}

\section{Research Design}

The Research Design method is deemed to employ direct interviews as a tool for investigating the Research Problem. These interviews are based on open-question sessions with fixed timing for 1 hour. The advantages of using direct interviews are related to the indepth information, openness in discussions, and direct hands-on approach when exploring such kind of sensitive corporate issues. The information provided by the company supports the analysis of its internal environment. This will define the current innovation performance status and also the current positioning of the wine industry enterprises.

\section{Data Collection}

Data Collection is based on interview replies and statements. They were our primary source of information. Based on data gathering, analytical information was synthesized and produced for the purposes of the research. In fact, in the research data gathering as a technique was formalized through our direct interaction in a discussion format with the Top Executives and the CEOs. Thus, we got consistent information on the problem under scrutiny. In addition, to the interview sessions, desk research was conducted, in order to counter-check the information against inconsistencies and to build correct and up-todate logical models of reasoning.

\section{Unstructured (in-depth) Interviews}

The type and content of the in-depth interview toolkit may vary depending on the following four factors: 1) the person who conducts the survey; 2) the subject of the study (it is important whether facts, assessments, opinions, ideas will be studied about a particular political or social phenomenon); 3) the focus of the survey; and 4) the selection of respondents.

A major advantage of in-depth interviews is the opportunity they provide to analyse unexplored facts and events. In literature, very often in-depth interviews are referred to as pilot studies (2). Therefore, the researcher is interested to meet with as many people as possible in order to maximize his/her understanding of the subject of analysis and to get an immediate impression of how the different actors interpret the studied events.

In the current research, conducting in-depth interviews with some wine growers in SMEs gives a more in-depth and specific picture of the nature of their innovation challenges. Alongside, in-depth interviews as a part of the conceptual model for investigating the innovation activity (3) helped us to understand better the situation behind a specific answer from the survey that we are conducting with the aim of realizing the scientific project for fundamental research.

\section{RESULTS AND DISCUSSION Overview}

The objective of this phase of data collection was to ask the managers and specialists about the proposed conceptual model for investigating the innovation activity of enterprises (3) and get their overall feedback and insights into the concept of innovations. The results of previous researches of the team (4), i.e. a pilot study and more precisely the results from Phase Two, namely in-depth interviews among SMEs wine producers from the Plovdiv region, gave us very interesting data. Furthermore, it gave us some valuable ideas on the improvement of our methodology. In addition, we included in the research representatives of wine industry enterprises located in different wine regions in Bulgaria that gave us the opportunity for benchmarking. Respondents were asked a series of questions to establish the type and origin of their business, their personal background and experience with management, and then questions dealing more specifically with implementation of innovations. We asked a broad range of questions focused on their understanding of the necessity and specificity of innovations and the implementation of innovation strategies.

While the interviews sought confirmation of the proposed ideas, so were modifications and emergent concepts that might influence the development of the construct. Essentially, this phase of the research was designed to compare the largely theory and literature-based conceptualization of innovations and 
innovation strategies with the practical experience and knowledge of managers and specialists.

\section{Sample Selection}

The study consisted of interviewing 15 managers and specialists who were picked from a convenience sample of SMEs from wine industry located in Bulgaria. As no such research was conducted in the companies before, it took some months to make the Top Management and Wine Specialist (oenologist, technologist, etc) willing to cooperate and finish the research. We selected a potential pool of 20 wine producers to contact for interviews based on our strongest personal relations (given the time and effort commitment necessary for the interview phase). All of the respondents were contacted
ANGELOVA M., et al. throughout January 2020 to April 2020, of which 15 agreed to be interviewed. The enterprises are located in the area of Sofia, Plovdiv, Asenovgrad, Harmaly, Panagyurishte, Sandanski, Stara Zagora, Veliko Tarnovo. In this sense, we had included representatives by the two wine regions in Bulgaria - Danubian Plain and Thracian Valley (according to data of the State Gazette, issue 67/16.08.2005 there are two wine regions for the production of regional wines in Bulgaria). These respondents included a diverse collection of men and women from the wine industry. The revenue of the investigated enterprises for $2018^{1}$ ranges from 0.3 to 23 million leva (BGN). Table 1 summarizes the characteristics of the participants and their organizations.

Table 1. List of Interview Participants; ${ }^{*} \boldsymbol{F}-$ Founder (co-founder); ${ }^{*} \boldsymbol{O M}-O$ wner-Manager; ${ }^{*} \boldsymbol{M}$ Manager; *S - Specialist; Micro enterprise; Small enterprise; $* \boldsymbol{M S}$ - Medium-sized enterprise

\begin{tabular}{|l|c|c|c|c|c|c|c|}
\hline $\begin{array}{c}\text { Com- } \\
\text { pany }\end{array}$ & $\begin{array}{c}\text { Year } \\
\text { founded }\end{array}$ & $\begin{array}{c}\text { N of } \\
\text { employees }\end{array}$ & $\begin{array}{c}\text { Respondent } \\
\text { Title }\end{array}$ & Sex & $\begin{array}{c}\text { Origin in } \\
\text { company* }\end{array}$ & $\begin{array}{c}\text { Size of the } \\
\text { enterprise }\end{array}$ & $\begin{array}{c}\text { Interview } \\
\text { duration }\end{array}$ \\
\hline ID:1 & 1999 & 44 & President & Female & F, OM & Small & $38: 00$ \\
\hline ID:2 & 1999 & 44 & Technologist & Male & S & Small & $55: 00$ \\
\hline ID:3 & 2001 & 55 & CEO & Female & M & MS & $1: 54: 02$ \\
\hline ID:4 & 2005 & 38 & CEO & Female & F, OM & Small & $1: 24: 05$ \\
\hline ID:5 & 1995 & 8 & Pres \& CEO & Male & F, OM & Micro & $48: 15$ \\
\hline ID:6 & 1999 & 134 & Technologist & Male & S & MS & $1: 12: 00$ \\
\hline ID:7 & 1947 & 212 & Pres\&CEO & Male & OM & MS & $1: 01: 00$ \\
\hline ID:8 & 2014 & 6 & CEO & Male & Co-F, OM & Micro & $49: 25$ \\
\hline ID:9 & 2005 & 15 & Technologist & Male & S & Small & $31: 03$ \\
\hline ID:10 & 2005 & 15 & President & Male & F, OM & Small & $42: 03$ \\
\hline ID:11 & 2017 & 7 & Pres \& CEO & Male & F, OM & Micro & $39: 10$ \\
\hline ID:12 & 2005 & 48 & Pres \& CEO & Male & F, OM & Small & $43: 04$ \\
\hline ID:13 & 2001 & 65 & CEO & Female & M & MS & $35: 00$ \\
\hline ID:14 & 2003 & 35 & Technologist & Male & S & MS & $25: 00$ \\
\hline ID: 15 & 2009 & 25 & Oenologist & Male & S & Small & $45: 00$ \\
\hline
\end{tabular}

Source: Own data

\section{Interview Approach}

Each of the managers/specialists was interviewed using semi-structured interview techniques where a series of questions were developed in advance. Follow-up prompts or questions were asked where there appeared to be more insights to gain. The interview questions began with "grand tour" type questions about the origin of the business, the respondent's involvement, and the original opportunity.

Questions about the hiring of early stage employees and the development of innovation strategy at the organization were also asked. The interview then focused on general questions about the proposed conceptual dimensions (e.g., Approbation of Innovation,
Effectiveness, Innovation Strategy, Innovation Culture and Change Culture, etc.). The interview concluded with a discussion of any final thoughts the respondent might have on the innovations and innovation strategies in general, such as how it had changed over time and what future innovation activity concerns he or she might have.

Twelve of the interviews were conducted at the manager's place of business while three were conducted via an Internet video conference.

\footnotetext{
${ }^{1}$ The Revenue data is based upon official documents published in the web site of Ministry of Justice Registry Agency in Bulgaria, Commercial Register, online available on:

https://public.brra.bg/CheckUps/Verifications/Verificatio nPersonOrg.ra [accessed on April, $5^{\text {th }}, 2020$ ]
} 
In addition to its importance in evaluating the innovation activity, the interview data helped to provide much needed context, nuance, and clarity to the broader innovation picture. In addition to specific thoughts and insights around the conceptual issues (i.e. the innovation dimensions and the concept of innovation strategy implementation), the participants discussed their perceptions of how and why their innovative cultures developed as they did, the salient features of their particular cultures, and the importance of core values in the organization. Innovation strategy and implementation of innovations were clearly an issue that the participants thought about, were concerned about, and had put a great of effort into shaping or managing, as best they could.

The following subsections explore the managers' thoughts about the implementation of innovation with respect to the proposed conceptual model and their overall insights into the innovation concept.

\section{The Nature of Innovations and Innovation Strategy}

To begin the interviews, the managers/specialists were asked a series of broad questions about their definition of innovation and what they thought the innovation strategy of their organization was like. Respondents were also asked if an "innovation strategy" meant anything to them and what that might be. The purpose of these general questions was to get a sense of what the participants thought about innovations (if at all) and how innovations were perceived by them and by extension, their organization. When asked these questions the respondents reported a variety of ideas and opinions. For example, innovation was the "future" of the company, "how we plan to do things", an "extension of the founder/CEO", how people "behave inside and outside the organization", and "how people think and act in future perspective." Although not expressed in the same words, collectively these ideas describe a central sense of innovation that closely matches the Schumpeter's (5) view of innovation.

Overall, the data presents several key insights into the nature of Innovations. Innovation Strategy was thought to represent the values and beliefs which underlie actions and behaviors in the firm, or colloquially, "the way we plan to do things" and the reasons behind them. An Innovation Strategy, echoing the core attributes of innovations, incorporate notions of risk taking and flexibility, among others, in the service of opportunities. Finally, Innovation Strategy is a group endeavour which may be hard to come by, even in firms where such a culture would be expected to be found. These sentiments, taken as a whole, aligned with the proposed conceptualization of Innovation Strategy (6).

These ideas appear to support the view of Innovations as an organizational culture focused on opportunities and the things that are necessary to identify/develop them and ultimately act on them.

Table 2 presents a selection of the evidenced data that supports this position.

\section{ANALYSIS AND RESULTS}

The respondents were asked to describe a successful innovation program according to their own point of view. In most cases, through these techniques, they make a projection of their own problems and give solutions through creating the "ideal type" Innovative Enterprise. The model of a successful innovation program can be connected with the development stage of every enterprise. For example, in the cases where the enterprise is a start-up the successful enterprise is imagined in the most ideal picture with minimum concrete data - the vision of the respondents is abstract following the line that all the employees are motivated and dedicated to the special cause in a sustainable enterprise. Correspondingly, the backbone is the enterprises with experience and history behind them that really work successfully - there is usually a successful enterprise, which is considered "more than the same", either staff growth, investment, geographic expansion in other regions.

Another distinguishing feature of a successful enterprise is self-sufficiency, especially in the financial aspect. There are many examples of where operating businesses have certain financial dependencies - from municipal budgets (in the case of enterprises that are part of municipal structures), from project funding that is unsustainable to the extent unpredictable by donors who would also end funding. Wine producers declare that they had received funds by numerous programs such as "Special Accession Programme for Agriculture and Rural Development" - SAPARD, The Phare Programme, Rural Development Programme 2014-2020, Measure 126 - Equipment, etc. 
Table 2. The nature of Innovations and Innovation Strategy

\begin{tabular}{|c|c|}
\hline $\begin{array}{l}\text { Size of the } \\
\text { Enterprise }\end{array}$ & Examples \\
\hline $\begin{array}{c}\text { Small } \\
\text { Wine } \\
\text { Producer }\end{array}$ & $\begin{array}{l}\text { "It's the ability as an entrepreneur to see opportunities combined with the resourcefulness of a } \\
\text { farmer who has just lived his life dealing with what is. Taking advantage of whatever } \\
\text { opportunities come his way..." }\end{array}$ \\
\hline $\begin{array}{l}\text { Micro } \\
\text { Wine } \\
\text { Producer }\end{array}$ & $\begin{array}{l}\text { "the first word that comes to mind is 'opportunity'...it's dynamic, changing, it's risky - not quite } \\
\text { - but thrilling for the manager. Developing the innovation strategy for the people - it's hard, it's } \\
\text { uncertain let's say, there is uncertainty involved and flexibility is required to not get too attached } \\
\text { to a routine way of doing things." }\end{array}$ \\
\hline $\begin{array}{l}\text { Small Wine } \\
\text { Producer }\end{array}$ & $\begin{array}{l}\text { "we are building something from scratch, ... we innovate focused on new machines and } \\
\text { equipment ... replacing human labor as much as possible" }\end{array}$ \\
\hline $\begin{array}{l}\text { MS Wine } \\
\text { Producer }\end{array}$ & $\begin{array}{l}\text { "The implementation of innovations first and foremost is to impress. It is the lifeblood of our } \\
\text { organization. We have to have the can-do attitude to solve the problem for a customer in the } \\
\text { fastest and most convenient, most value-added way..." }\end{array}$ \\
\hline $\begin{array}{r}\text { Smal } \\
\text { Pro }\end{array}$ & "[innovation strategy] would be outside-the-box, freedom, willing to take a risk." \\
\hline $\begin{array}{l}\text { Micro Wine } \\
\text { Producer }\end{array}$ & "the innovation strategy...it's about having ideas and understanding how to execute the ideas..." \\
\hline $\begin{array}{l}\text { MS } \\
\text { Wine } \\
\text { Producer }\end{array}$ & $\begin{array}{l}\text { "it is a certain passion, excitement, and nimbleness that you bring to a situation. ... that's the } \\
\text { nature of playing a game, that is the nature of a season, there is the odd challenge, but here is what } \\
\text { we have to do and here is the tweak up of how we are going to make it if we just keep going } \\
\text { forward." }\end{array}$ \\
\hline $\begin{array}{l}\text { Small } \\
\text { Wine } \\
\text { Producer }\end{array}$ & $\begin{array}{l}\text { "[it is] a culture of empowerment and we want people to make decisions and if they make a } \\
\text { mistake then let's just talk about how we are going to solve it or fix it or make it so it doesn't } \\
\text { happen again." }\end{array}$ \\
\hline $\begin{array}{l}\text { Micro } \\
\text { Wine } \\
\text { Producer }\end{array}$ & $\begin{array}{l}\text { "innovation to me is a whole range of things, because you can be innovative in how you deliver } \\
\text { services, how you take care of customers, how you handle your own team members, that sort of } \\
\text { thing. Pretty broad and in just thinking differently than the norm..." }\end{array}$ \\
\hline $\begin{array}{l}\text { Small } \\
\text { Wine } \\
\text { Producer }\end{array}$ & $\begin{array}{l}\text { "the implementation of innovation strategy gives you a bit of the license to not miss out or look at } \\
\text { what's been done before or slot yourself into the best practice precedent - I think every decision } \\
\text { we make, we look at it with the lens of do we want to follow or do we want to lead. Sometimes } \\
\text { you want to follow, there is nothing inherently bad about that, but it's just that the rules aren't as } \\
\text { tight when you have a clear and prospective innovation strategy." }\end{array}$ \\
\hline
\end{tabular}

Source: Own data

In the answers of the respondents in some enterprises was identified an inconsistency. On the one hand, they claim that they are not innovative (3 companies), do not implement innovative strategies, but at the same time, they offer interesting new services, such as the opportunity for customers to make their own batch of 300 bottles of wine, their own blend, wine tourism with different wine packages, etc. They do not understand the nature and types of innovations and at the same time they do not realize that their actions are innovative.

There are conflicting sentiments regarding the production of new wines. 3 of the enterprises have included in their assortment orange wine, blue wine, wine with roses, white wine from red grapes, green wine, etc., while others rely on traditional Bulgarian varieties. More than half of the organizations are focused on the concept of returning traditions 100 years ago, before modernization. One of the wineries wants to produce handmade boutique wine and pure wines. But most of the participants claim that "wine is fashion, but the customer should not be snobbish, i.e. he/she should consume wine that he/she personally likes, not what others direct him to buy".

All respondents are adamant about the introduction of new machinery, equipment and technology, and are participating in various funding programs. New enzyme preparations and the application of drones to reduce the consumption of preparations are introduced to improve quality and yield. They are introducing a winery (wine combine) and other equipment to reduce the human factor. The winemakers are of the opinion regarding the lack of qualified specialists who have the experience and knowledge to develop the enterprise. Affidavit of support of the abovementioned, none of the enterprises had introduced organizational-managerial innovations. They are focused in product, process, and technological innovations. 
ANGELOVA M., et al.

$82 \%$ of the respondents have implemented ancillary services, believing that "the money is in the services, not in the product", incl. wine tourism, wine packages, sale of local products. They possess a hotel or guest house, restaurant, degustation room where they can develop wine tourism by themselves. Working with partner organizations and tourist agencies in Bulgaria and abroad, for 2019 they have guests from more than 50 countries. One of the cellars develops a fishery and a farm for the production of specialized goat meat in addition to the accompanying activities.

Most wine producers participate in different competitions and have various rewards. 53\% of them have exported in the EU and other countries like Vietnam, Russia, etc. All but one of the enterprises are focused in the production of boutique wines with high quality, not a commercialized product, based on the statement that they are trying "to produce good wine at a reasonable price with high quality".

The leading weakness for the development of the sector is the lack of a strong branch organization, the inability to create clusters at the moment, the insufficient advertising on international markets. They exemplify France (Bordeaux and Marseille region), Italy, Spain, and Portugal and the way in which their wines are promoted. Till now, there are some examples of regional grouping experiences in Bulgaria, such as the Veliko Turnovo Wine Destination and Southern Sakar. Many investigations are focused on the necessity to develop wine clusters (7) but respondents state that the Bulgarian winegrowers need more time to mature for the idea.

A huge problem for wine producers is the $50 \%$ reduction of the raw material in Bulgaria, and as a result in 2019 the vineyards are twice less than in 2006. This is the reason for the inability of Bulgarian producers to respond to the quantities demanded from the foreign markets. They are directing funds to increase their own vineyards. One of the cellars is opening two new production bases in 2020, which is using the Charmat method for the production of sparkling wine, making them unique for Bulgaria. None of the managers and technologists are focused in the production of $\mathrm{BIO}$, Organic and Eco wine because of the specific requirements and procedures in this type of wine.

As this research is a part of a project, in other papers (8) we distinguished several types of innovations. The results of in-depth interviews according to the implementation of innovations is summarized in Table 3.

Most answers to the question "How do you measure innovation?" are incomplete or contradictory. One of the reasons that a very small sample of all companies in the world have formal innovation metrics is because this simple question does not have a simple answer. Metrics can be important levers of innovation - for driving behavior, as well as evaluating the results of specific initiatives. Defining the right metrics for the wine industry business can be tricky. There's generally no one right answer and agreeing on what to measure can feel more like art than science.

The heart of the problem is that today's competitive environment is radically different from the industrial environment in which traditional innovation metrics were born. Because most metrics programs begin with benchmarks of established companies that have been successful with new products, metrics tend to revert back to traditional measures of $\mathrm{R} \& \mathrm{D}$ or technology investment and effectiveness. If we focus on these two parameters, 14 (93.3\%) of the companies apply innovations in $\mathrm{R} \& \mathrm{D}$ and new technologies. In line with this, it can be concluded that wine producers possess high innovation index. Across the Fortune 1000 (9) that do possess innovation metrics, for example, the most prevalent metrics include: Annual R\&D budget as a percentage of annual sales, Number of patents filed in the past year, Total $R \& D$ headcount or budget as a percentage of sales, Number of active projects, Number of ideas submitted by employees, Percentage of sales from products introduced in the past X year(s).

The participants do not implement these metrics, do not have patents and cannot evaluate whether or not have active projects, R\&D budget as a percentage of sales, etc. While some of these metrics are valuable for driving investment in innovation and evaluating results, they provide a limited view. In today's environment in which "open innovation" (13\% of respondents apply) can create differentiation and competitive advantage, for example, some of these metrics actually inhibit strategic innovation. And in an environment in which disruptive innovation (10) must be wholeheartedly embraced as a core strategy, fundamentally new types of behaviors are required, and subsequently new 
ANGELOVA M., et al.

structures and related metrics to drive these behaviors. Affidavit of support of the above mentioned, it's not possible to calculate the Innovation Index for the wine industry enterprises which participated in the interview.
All of the participants state that the regulatory mechanisms of the institutions are not well developed and "Bulgarian institutions are an obstacle not a supporter for the development of the industry and business initiatives".

Table 3. Types of implemented innovations by wine producers

\begin{tabular}{|c|c|c|c|c|c|}
\hline Criteria & \multicolumn{5}{|c|}{ Types of innovations } \\
\hline \multirow[t]{2}{*}{ (1) According to the object of innovation } & product & process & marketing & \multicolumn{2}{|c|}{$\begin{array}{c}\text { organizational- } \\
\text { management }\end{array}$} \\
\hline & $100 \%$ & $60 \%$ & $33 \%$ & \multicolumn{2}{|c|}{0} \\
\hline \multirow{2}{*}{$\begin{array}{l}\text { (2) According to the degree of radicalism, the } \\
\text { depth of change and the time-lag between the } \\
\text { idea and its practical application }\end{array}$} & basic & improved & \multicolumn{3}{|c|}{ pseudo-innovation } \\
\hline & $13 \%$ & $66 \%$ & \multicolumn{3}{|c|}{$6.66 \%$} \\
\hline \multirow[t]{2}{*}{ (3) According to the source } & $\begin{array}{l}\text { innovation from } \\
\text { research and } \\
\text { development }\end{array}$ & $\begin{array}{l}\text { own } \\
\text { company } \\
\text { innovation }\end{array}$ & \multicolumn{3}{|c|}{ innovation from other sources } \\
\hline & $80 \%$ & $60 \%$ & \multicolumn{3}{|c|}{$33 \%$} \\
\hline \multirow[t]{2}{*}{ (4) According to the company strategy } & Open innovation & \multicolumn{4}{|c|}{ closed innovation } \\
\hline & $13 \%$ & \multicolumn{4}{|c|}{$80 \%$} \\
\hline \multirow{2}{*}{$\begin{array}{l}\text { (5) According to the field in which innovation } \\
\text { is realized }\end{array}$} & industrial & \multicolumn{4}{|c|}{ managerial } \\
\hline & $100 \%$ & \multicolumn{4}{|c|}{$6.66 \%$} \\
\hline \multirow[t]{2}{*}{ (6) According to the material form } & \multicolumn{2}{|c|}{$\begin{array}{l}\text { material (represented as a material } \\
\text { object - product or technology) }\end{array}$} & \multicolumn{3}{|c|}{$\begin{array}{c}\text { non-material (no substance form - } \\
\text { legal innovations) }\end{array}$} \\
\hline & \multicolumn{2}{|c|}{$20 \%$} & \multicolumn{3}{|c|}{$13 \%(2$ enterprises $)$} \\
\hline \multirow[t]{2}{*}{$\begin{array}{l}\text { (7) According to the source of ideas, the } \\
\text { emergence of innovation can be triggered }\end{array}$} & by specific users & $\begin{array}{l}\text { from a new } \\
\text { discovery }\end{array}$ & \multicolumn{3}{|c|}{ from the company's own needs } \\
\hline & $27 \%$ & $20 \%$ & \multicolumn{3}{|c|}{$66 \%$} \\
\hline \multirow[t]{2}{*}{$\begin{array}{l}\text { (8) According the novelty of the company, the } \\
\text { market and the particular consumer } \\
\text { respectively }\end{array}$} & $\begin{array}{l}\text { new products } \\
\text { globally }\end{array}$ & $\begin{array}{l}\text { a brand new } \\
\text { product for } \\
\text { the company } \\
\text { with which it } \\
\text { is entering a } \\
\text { new market } \\
\text { for it }\end{array}$ & $\begin{array}{l}\text { new product, } \\
\text { which } \\
\text { complements } \\
\text { the existing } \\
\text { product range } \\
\text { of the } \\
\text { company }\end{array}$ & $\begin{array}{l}\text { sophisti- } \\
\text { cated } \\
\text { company } \\
\text { product }\end{array}$ & $\begin{array}{l}\text { re- } \\
\text { positi } \\
\text { oned } \\
\text { comp } \\
\text { any } \\
\text { produ } \\
\text { ct }\end{array}$ \\
\hline & 0 & $6.66 \%$ & $93.3 \%$ & $66 \%$ & $\begin{array}{c}33.3 \\
\%\end{array}$ \\
\hline \multirow[t]{2}{*}{$\begin{array}{l}\text { (9) According to the impact of innovation on } \\
\text { consumer habits }\end{array}$} & $\begin{array}{l}\text { innovations, } \\
\text { uninterrupted } \\
\text { consumer habits }\end{array}$ & \multicolumn{2}{|c|}{$\begin{array}{l}\text { innovations, changing } \\
\text { consumer habits }\end{array}$} & \multicolumn{2}{|c|}{$\begin{array}{l}\text { innovation, } \\
\text { creating new } \\
\text { consumer habits }\end{array}$} \\
\hline & $53.3 \%$ & \multicolumn{2}{|c|}{$20 \%$} & \multicolumn{2}{|c|}{$6.66 \%$} \\
\hline
\end{tabular}

Source: Own data

Many surveys assess the impact of entrepreneurial skills to launch managerial initiatives in the sphere of innovation activities. At most valuable level is the communication skills, the initiative, the ability to work in a team and managerial skills and abilities of the manager. The lack of organizational-management innovations is an issue that must be checked with the results from the inquiry card. It's a possible limitation that at the time of the interview the respondents emphasize only toward the product and its quality and as a consequence, all the efforts are focused in this field.
After all, if a generalized model of a successful Innovative Enterprise from the wine industry in Bulgaria has to be drawn, it may be described as follows: A successful Innovative Enterprise is a functioning enterprise with a clear vision and practice of identifying significant, positive change and introducing it in the enterprise environment. It is focused on improving or replacing business processes to increase efficiency and productivity, and on producing good wine at a reasonable price with high quality.

According to the in-depth interview results, when people evaluate the product/service as 
good and use it more than ones, that means that the enterprise reaches its goals.

The dominant qualities of interviewed wine growers are: Communication skills, Activity and Initiative, Ability to work in a team, Proactiveness, and Strategic planning capabilities. What became apparent when reviewing the questionnaire items in light of the interview results was that some of the questionnaire items did not appear to sufficiently capture the concepts intended in the development of the innovations. After the interviews were conducted and we had an opportunity to think through and review the transcripts, there was a sense of disconnection between some of the items and the sentiments expressed by the respondents. While some of the ideas seemed to be relatively well captured, others did not. This perhaps should have been expected that not all of the concepts would be considered highly relevant by the respondents, this might have been exacerbated by items which may ultimately have been conceptually unrelated.

However, the results from the interviews including notions of strategic planning, shared struggle, and motivated representatives (managers and specialists) seemed to describe different concepts than work expectations and job responsibilities. Instead, the desired focus was more about team work and mutual support. Accessing cohesion through work expectations and job responsibility may be too indirect compared to more direct questions such as "I feel like I can count on others in the organization for support".

Several questions were oriented more towards generalized risk-taking and innovation rather than changing to pursue or develop new opportunities. These risk-taking and innovation items seemed too abstract and removed from the intended notion of innovation and change for or because of opportunities. While these might be related to innovation and change, conceptually these might be reflecting different ideas, for example, fear of sharing ideas might be more related to workplace bullying. Different items such as "our organization moves quickly to go after new opportunities" and "more experienced employees encourage new people to experiment with new ideas or ways of doing things" were generated as replacements instead. These items seemed to much better reflect the intended concepts in this dimension.

\section{CONCLUSION}

ANGELOVA M., et al.

This paper outlined the objective, procedure, sample selection, and analysis and results of Phase One of the research project data collection, which was based on interviews with practicing managers/specialists. The purpose of this phase was to explore the domain of Innovation and compare the proposed conceptual model against the experiences, expertise, and insights of managers and specialists. The intention was to evaluate the real world fidelity of the model and to compare our conceptual thinking and interpretation against practitioner-described reality.

The 15 interviews with managers/specialists produced a wealth of data that largely supported the conceptual thinking of the model while also providing important context, nuance, and explanation to the respondent's perspectives on Innovation Strategy. One of the interesting findings was that although some of the wine producers implement innovations they don't realize it. Furthermore, the focus of their innovations is in the product, process, and technological innovations. The latter comes from their effort to reach a balance between quality and price. As concerns the role of institutions for the innovation activity of wine producers, it looks like that the institutions are more like an obstacle rather than a support for such activity.

This rich qualitative data helped to ground the model and provide evidence for the veracity of the proposed dimensions. This data also provided important foundational evidence for future innovation work which might explore the formation of innovation strategy and its change in organizations.

\section{ACKNOWLEDGMENTS}

The research is part of a project KP-06M25/5/17.12.2018, financed by the National Science Fund of Bulgaria, Ministry of Education and Science.

\section{REFERENCES}

1. Dimitrova, G., Angelova, M. and Pastarmadzhieva, D., Innovation Activity as an Element of the Competitiveness of Wine Industry: a Conceptual Framework. Trakia Journal of Sciences, 17 (1): 221-226, 2019.

2. Shoukry, D., S. and Wang, C. K., The Management of Innovation: Strategy, Structure, and Organizational Climate. IEEE Transactions on Engineering Management, 40 (1): 14-21, 1993. 
3. Angelova, M. and Pastarmadzhieva, D., Conceptual Model for Investigating the Innovation Activity of Enterprises. International scientific journal Science. Business. Society. 5 (1): 17-19, 2020.

4. Angelova, M. and Pastarmadzhieva, D., Development of Bio-Based Economy: Entrepreneurial Endeavors and Innovation across Bulgarian Wine Industry. Journal of International Studies, 1: 277-291, 2020. doi:10.14254/2071-8330.2017, in press

5. Schumpeter, J. A., Capitalism, socialism and democracy. George Allen and Unwin, London, 1976.

6. Edwards-Schachter, M., The nature and variety of innovation. International Journal of Innovation Studies, 2 (2): 65-79. 2018.

7. Dimitrova, G., The wine cluster challenge in Bulgaria - mission (im)possible. Conference proceedings Anniversary
ANGELOVA M., et al. Industrial Growth Scientific Conference 2018 EN: 82-91. 2018.

8. Angelova, M., Pastarmadzhieva, D., Dimitrova, G. and Georgiev, P., Innovative Practices in Wine Industry: Opportunities for Competitiveness Enhancement in Bulgaria. International conference on Creative Business for Smart and Sustainable Growth (CreBus 2019), IEEE, DOI: 10.1109/CREBUS.2019.8840046, https://ieeexplore.ieee.org/document/ 88400 46, 2019.

9. https://www.innovationpoint.com/innovationmetrics.htm [accessed April, 07th 2020]

10.Ilieva-Nawfal, E., Radical innovations as a drive of Industrial Revolutions. Proceedings of $13^{\text {th }}$ conference for young researchers Technical Sciences. Industrial Management. 1 (3): 17-20. 2020. 